\title{
Zoledronate Trisodium
}

National Cancer Institute

\section{Source}

National Cancer Institute. Zoledronate Trisodium. NCI Thesaurus. Code C80325.

The trisodium salt form of zoledronate, a synthetic imidazole, third generation bisphosphonate analog of pyrophosphate with antiresorptive activity. Zoledronate binds to hydroxyapatite crystals in the bone matrix and inhibits farnesyl pyrophosphate (diphosphate) synthase, thereby preventing protein prenylation within the mevalonate pathway. This leads to the loss of downstream metabolites essential for osteoclast function, leading to the induction of apoptosis and eventually, osteoclast-cell death. By preventing osteoclast-mediated bone resorption, zoledronate decreases bone turnover and stabilizes the bone matrix. 